\title{
New Meat on the Block: Factors Influencing India's Gen Z's Decision to Purchase Plant-based Meat
}

\author{
Nikita Dhawan ${ }^{1}$, Kah Ying Choo² \\ ${ }^{1}$ American Embassy School, New Delhi, India \\ ${ }^{2}$ Awakening Minds, Singapore \\ DOI: https://doi.org/10.47611/jsrhs.v10i2.1427
}

\section{$\underline{\text { ABSTRACT }}$}

There have been increasing concerns regarding the meat industry due to its negative influence on the environment, such as freshwater pollution, biodiversity loss, and increased methane emissions. These concerns have sparked the public's interest in plant-based meat, the demand for which is expected to reach USD 27.5 billion by 2025 . This study evaluated the factors influencing the decision of India's Gen Z (aged 15-25) to purchase plant-based meat by conducting an online survey using a mixed method research approach. Among the eight different factors examined, the study found environmental consciousness as one of the highest-rated factors in all the three categories of respondentscombined (vegetarians and non-vegetarians), vegetarians, and non-vegetarians-in influencing their decision to purchase plant-based meat. This finding mirrors the growing environmental awareness of Gen Z globally. Health/safety was another top-rated factor for all three groups, possibly due to the increasing concern of zoonotic diseases, such as COVID-19. Conversely, price, convenience, and food curiosity were the least influential, highlighting the Indian market's unique characteristics. As a significant majority of young Indian adults live with their parents, plant-based companies targeting Gen Zs need to consider India's family-oriented culture and the parents' dominant role in determining meal choices at home. While companies could incorporate plant-based meat products into traditional food and wellknown dishes to appeal to parents, companies can also target the more independent Gen Zs by emphasizing plantbased meat as a sustainable alternative to traditional meat. Additional nuanced marketing strategies for vegetarians and non-vegetarians have also been discussed in this paper.

\section{Introduction}

The meat industry is deeply beloved and popular amongst many cultures for various reasons (Persistence Market Research, n.d.). Not only is meat a highly nutritious source of protein, but it is also widely perceived to be delicious by meat-eaters (Robinson, 2017). Due to growing populations and sociocultural factors, the meat industry is growing faster than ever. The average global per capita meat consumption has nearly doubled from $23 \mathrm{~kg}$ to $43 \mathrm{~kg}$ over the last 50 years (Devlin, 2018); in the previous 20 years alone, meat consumption has increased by $58 \%$ to reach 360 million tons (Whitnall \& Pitts, 2020). According to Nozaki's (2016) “The Future of Global Meat Demand," global meat consumption is estimated to reach 460 million tons a year by 2050 .

The rapid growth in the demand for meat has, however, exerted a toll on the ecosystem. The livestock industry engages in practices that pollute freshwater with chemicals, contribute to the loss of biodiversity (since forests and wild habitat are used as agricultural land to grow animal feed), and emits methane that causes the "greenhouse effect" (Heilig, 1994). According to Devlin (2018), livestock production accounted for $15 \%$ of all carbon dioxide, methane and nitrous oxide emissions in 2018.

As environmental consciousness increases, the public has begun to question whether the products they buy are beneficial to the planet, causing the "responsible consumer base" to grow (Gadenne et al., 2009). This development 
has catalyzed consumption patterns of food that incentivize large food companies to reevaluate meat production and explore alternatives. According to Keegan Kuhn, Co-producer and Co-director of Cowspiracy: A Sustainable Secret, a documentary film, "corporations are just going to follow the dollar, and follow consumer demand, which hopefully will force them to switch to sustainable, plant-based agriculture" (Hancox, 2018, para. 20).

One response to these trends is the development of plant-based meat as a meat substitute designed to mimic meat in taste, texture, smell, appearance, and protein of meat (Bridgeman, 2020; Dion et al., 2020). Plant-based meat made entirely from plants does not require the warehousing or slaughtering of animals (Animal Legal Defense Fund, n.d.). Moreover, plant-based meat has another positive side of appealing to the environmentally-conscious. According to The Good Food Institute, an international non-profit organization that promotes plant-based alternatives, plantbased meat uses 47-99\% less land and emits 30-90\% fewer greenhouse gases. In contrast to traditional meat, plantbased meat does not require raising livestock, which uses significant agricultural land and emits substantial greenhouse gases. Furthermore, the GFI report explains how plant-based meat cuts out the primary water requirement that conventional meat requires since plant-based meat is already a final product ("Plant-based Meat for a Growing World," 2019).

The plant-based meat market is growing rapidly: It is expected to grow from USD12.1 billion in 2019 to approximately USD 27.9 billion by 2025 [MarketsAndMarkets Research Private Ltd. (MAM), 2020a]. Furthermore, the outbreak of COVID-19, a zoonotic disease, may accelerate the growth of sustainable meat products due to increasing health concerns from animal-borne diseases (germs that pass between animals and humans) (MAM, 2020b; Komba et al., 2012).

To tap into the alternative meat markets' full potential, food companies have started reevaluating their strategies and developing marketing techniques, including marketing segmentation and integrated-segregated strategies to attract consumers (Szejda \& Parry, 2020; Ignaszewski, 2020). Specifically, businesses and companies can implement targeted marketing strategies by identifying green customers and employing segmentation practices based on specific criteria, such as environmental consciousness (Su et al., 2019). For example, a study analyzing the factors affecting consumers' purchase of plant-based and cultivated meat illustrated that sustainability and food curiosity were two of the main positive factors behind their purchases (Hwang et al., 2020). On the other hand, a Good Food Institute study concluded that foundational values such as taste, cost and convenience dictate consumers' food choices. (Szejda et al., 2020). Other factors influencing consumer purchases of plant-based meat in Sweden include concern for the environment, a good taste, and a good feeling from buying the product, according to a recent study by a Swedish university on consumer behavior (Mousel \& Tang, 2016).

To date, the studies have primarily focused on adults, with comparatively fewer studies on the perspectives of Gen Z (born between the mid-1990s and early 2010s) towards sustainable products and brands (Insider Inc., 2020). For example, a research survey highlighted different segmentation markets of Gen Z in the US: $46 \%$ of the 1000 respondents categorized as "sustainable activists" (high environmental consciousness) and 47\% classified under "sustainable believers" (moderate ecological awareness) (Su et al., 2019). Another survey from "The State of Consumer Spending: Gen Z Shoppers Demand Sustainable Retail" revealed that $62 \%$ of the Gen Z participants would buy from sustainable brands (Jezerc, 2020). These studies reaffirm that Gen Z is highly focused on sustainability and environmental factors in their products.

The Gen Z consumer market bears close attention to companies: as of 2019 , Gen Z constituted $32 \%$ of the global population (Miller \& Lu, 2018). This segment will likely be instrumental in driving the growth prospects of the alternative meat industry. As Bollani et al. (2019) observed in a report on the younger generation's concept of sustainability in the food sector, it "could make an essential contribution to the debate among stakeholders on driving choices towards new production and consumption patterns" (p. 13).

A big gap in the current discourse is the lack of investigation of India's Gen Z's attitudes towards sustainable meat options in India. However, a recent research study compared plant-based meat and cultivated meat acceptance in the US, China, and India (Bryant et al., 2019), which include participants of all ages. It found that India and China have a higher social acceptance of sustainable meat than the US. The study suggests that Indian consumers, with the 
lowest level of meat attachment, are more aware of traditional meat's environmental and ethical issues. The results also showed higher food neophobia (fear of new things) and significantly lower meat attachment in India than in other countries (Bryant et al., 2019) - two conflicting forces that do not produce a clear-cut outcome to Indians' stance on plant-based meat. As India could be a large prospective customer for plant-based meat, companies could benefit from a study that explicitly evaluates the relevant factors influencing Gen Z's attitudes towards plant-based meats in India, to develop more targeted marketing strategies.

\section{Description of the Research Study}

\section{Research Aim and Research Approach}

This research study aimed to evaluate the factors influencing India's Gen Z's decision to purchase plant-based meat by using a mixed method approach. Specifically, under the quantitative approach, an online survey asked respondents to rate the importance of the eight influencing factors on their purchase decision on a scale of 1-7, " 1 " being the least important, and "7" being the most important (see the questionnaire in Appendix A).

The relevant factors have been identified as follows, based on an exhaustive review of literature:

- Nutrition: the abundance of nutrients, such as carbohydrates, fats, protein, minerals, which provides health benefits to the individual (The Department of Health, 2013);

- Taste: the sense by which food is distinguished (Bradbury, 2004);

- Food curiosity: the interest and desire to try new types of food;

- Animal welfare: ethical concerns about animal well-being when purchasing a food product (FoodPrint, 2020);

- Health and safety: the level of safety of the food product for human consumption, without any risks of bacteria, viruses, etc. (World Health Organization, n.d.);

- Environmental consciousness: the impact of the food product on the environment (Ghvanidze \& Velikova, 2016);

- Cost: the compatibility of the price with its value;

- Convenience: availability and accessibility of food products;

The hypotheses tested can be classified under four broad categories. The first category involves comparing the Gen $\mathrm{Z}$ respondents' mean ratings of the importance of the different factors in influencing their decision to purchase plantbased meat:

Null Hypothesis 1a: There are no differences in the mean ratings of importance between the factors that influenced the Gen Z respondents' decision to purchase plant-based meat.

Alternative Hypothesis 1b: There are differences in the mean ratings of importance between the factors that influenced the Gen Z respondents' decision to purchase plant-based meat.

Null Hypothesis 2a: There are no differences in the mean ratings of importance between the factors that influenced vegetarian Gen Z respondents' decision to purchase plant-based meat.

Alternative Hypothesis $\mathbf{2 b}$ : There are differences in the mean ratings of importance between the factors that influenced vegetarian Gen Z respondents' decision to purchase plant-based meat.

Null Hypothesis 3a: There are no differences in the mean ratings of importance between the factors that influenced non-vegetarian Gen Z respondents' to purchase plant-based meat.

Alternative Hypothesis 3b: There are differences in the mean ratings of importance between the factors that influenced non-vegetarian Gen Z respondents' to purchase plant-based meat. 
The second category determines whether the respondents' ratings of the importance of any of the factors influencing their decision to purchase plant-based meat impacted their likely weekly consumption of plant-based meat.

Null Hypothesis 4a: The factors that influenced Gen Z respondents' decision to purchase plant-based meat do not affect their likely weekly consumption of plant-based meat.

Alternative Hypothesis 4b: The factors that influenced Gen Z respondents' decision to purchase plant-based meat affect their likely weekly consumption of plant-based meat.

Furthermore, as the study sought to provide insights for companies seeking to enter the Indian market, it also elicited the respondents' perceptions on the price they were willing to pay for a plant-based burger, using the price of a conventional meat burger in urban India as a benchmark:

Null Hypothesis 5a: There is no difference in the mean price that the Gen $\mathrm{Z}$ respondents were willing to pay for a plant-based burger compared to a conventional meat burger.

Alternative Hypothesis 5b: There is a difference in the mean price that the Gen $\mathrm{Z}$ respondents were willing to pay for a plant-based burger compared to a conventional meat burger.

Finally, another hypothesis was formulated to determine if any factors that influenced the Gen Z respondents' decision to purchase plant-based meat also affected the price they were willing to pay for plant-based meat product:

Null Hypothesis 6a: The factors that influenced the Gen Z respondents' decision to purchase plant-based meat did not affect the price they were willing to pay for a plant-based meat product.

Null Hypothesis 6b: The factors that influenced the Gen Z respondents' decision to purchase plant-based meat affected the price they were willing to pay for a plant-based meat product.

Adding yet another layer to the investigation of the results distinguished the respondents based on their demographic information and dietary preferences, which provided additional results for different market segments.

\section{Data Gathering}

The online survey that targeted Indian residents aged 15 to 25 was distributed via WhatsApp, Instagram, and Facebook, with an accompanying invitation stating the research aim and reassuring the respondents of their anonymity and their data confidentiality (see Appendix B). In total, 176 respondents participated in the survey, excluding invalid respondents, thus constituting a good representative sample to evaluate perspectives towards plant-based meat.

\section{Data Analysis}

For the analysis of the data, descriptive statistics were used to determine the mean differences between the respondents' ratings as a whole, vegetarians only, and non-vegetarians only, to gain distinctive insights about the different categories. Moreover, one-way ANOVA tests were run three separate times to evaluate the statistical significance of the mean differences between the factors among the three types of respondents described above. Next, two multiple regression analyses were conducted on the overall group: (1) to evaluate the impact of the eight factors on the respondents' frequency of likely consumption of plant-based meat each week; and (2) the price they would be willing to pay for a plant-based meat burger. Finally, qualitative data were analyzed based on the respondents' answers to an open-ended question, asking them to elaborate upon the factors influencing their decision to purchase plant-based meat. 


\section{Results and Discussion}

In this chapter, the results from the statistical analyses, as outlined in the "Description of Research Study" section, are presented and examined in detail. The implications of the research outcomes pertaining to the influencing factors on the respondents' decision to purchase plant-based meat; the impact of the factors on their anticipated weekly plantbased meat consumption and the prices that they were willing to pay; as well as the discrepancy between the price that the respondents were willing to pay for a plant-based meat burger and the price of a conventional burger (INR 200).

\section{Evaluation of Influence of Factors on India's Gen Z's Purchasing Decisions of Plant-Based Meat} This section explores the relative influence of eight factors on Gen Z's opinions to purchase plant-based meat. Based on Figure 1, the factors, presented in order of influence from the most important to the least, are as follows: environmental consciousness $(M=6.00 ; S D=1.31)$; animal welfare $(M=5.97 ; S D=1.46)$; health/safety $(M=5.92 ; S D=$ $1.41)$; taste $(M=5.88 ; S D=1.55)$; nutrition $(M=5.33 ; S D=1.40)$; convenience $(M=5.29 ; S D=1.56)$; food curiosity $(M=4.91 ; S D=1.62)$; and cost $(M=4.77 ; S D=1.88)$.

\begin{tabular}{|c|c|c|c|c|}
\hline & Mean & Standard Error & Median & Standard Deviation \\
\hline Nutrition & 5.335227273 & 0.105870171 & 5 & 1.404526541 \\
\hline Taste & 5.880681818 & 0.116565337 & 6 & 1.54641395 \\
\hline Food curiosity & 4.914285714 & 0.122335548 & 5 & 1.618347187 \\
\hline Animal welfare & 5.971590909 & 0.110026259 & 7 & 1.459663277 \\
\hline Health/safety & 5.920454545 & 0.106430632 & 7 & 1.411961885 \\
\hline $\begin{array}{c}\text { Environmental con- } \\
\text { sciousness }\end{array}$ & 6.005681818 & 0.098856172 & 6 & 1.311475327 \\
\hline Cost & 4.767045455 & 0.142045455 & 5 & 1.884445904 \\
\hline Convenience & 5.297142857 & 0.117799832 & 5 & 1.558345297 \\
\hline
\end{tabular}

Figure 1. Descriptive Statistics: Influence of Factors on Respondents' Purchasing Decisions

A one-way ANOVA test was run to determine whether the differences in mean are significant. As shown in Figure 2, the results showed that the differences in the importance of factors are significant: $F(7,1398)=18.6$ (higher than the $F$ critical value of 2.02$), p<.05$.

\begin{tabular}{|c|c|c|c|c|c|c|}
\hline $\begin{array}{c}\text { Source of Varia- } \\
\text { tion }\end{array}$ & SS & $d f$ & $M S$ & $F$ & P-value & $F$ crit \\
\hline Between Groups & 307.1281861 & 7 & 43.87545516 & 18.66548475 & $6.53228 \mathrm{E}-24$ & 2.016117522 \\
\hline Within Groups & 3286.166266 & 1398 & 2.350619647 & & & \\
\hline Total & 3593.294452 & 1405 & & & & \\
\hline
\end{tabular}

Figure 2. One-way ANOVA: Ratings of Factors on Respondents' Purchasing Decisions

It is interesting to note that the general mean ratings are high across the board for all factors, ranging from 4.76 to 6 out of 7. This finding suggests that although some factors may be more important, none of the factors should be entirely ignored when developing marketing strategies for plant-based meat, since all the factors play a role in consumers' purchasing decisions. 
Environmental consciousness $(M=6.01)$ and animal welfare $(M=5.97)$ are the top two factors influencing the respondents' purchase decisions of plant-based meat. This essentially mirrors the trend of sustainability for Gen Z globally (BritainThinks, 2019). This thus bodes well for plant-based meat manufacturers. However, there are respondents such as the one below who expressed concerns on the overproduction of plant-based meat and its adverse ramifications for the environment:

I am mostly concerned about the environmental impact and ethical responsibility of these slaughterhouses. If plant-based were to become mainstream, then I worry that, in India, it would lead to overproduction of certain vegetation. This adversely affects soil fertility that damages the long-term food production of the country. I feel more research [should] be done with an Indian context in mind. Western ideas of plant-based food culture cannot work here.

Conversely, the three lowest factors were convenience $(M=5.29)$; food curiosity $(M=4.91)$; and cost $(M=4.76)$. The lack of importance of these three interrelated factors may be attributable to the specific characteristics of Indian families. First, the traditional structure of Indian families is collectivistic and encourages social interdependence within family members (Chadda \& Deb, 2013). A report from CBRE (2016), a global real estate firm, states that $82 \%$ of young Indians aged between 22-29 still live with their parents.

Furthermore, due to the culture of collectivism, Indian families often dine together. As such, parents have a significant influence on young adults' food choices and purchases. As Tulasi Srinivas' (2006) pointed out in "As Mother Made it: The Cosmopolitan Indian Family," dietary habits among cosmopolitan Indian families are inextricably interwoven with their affiliative desire to strengthen bonds within social groups (Srinivas, 2006). The emphasis on maintaining traditional food habits and the Indian culture across generations has created the impetus for cooking traditional Indian food for children to enlighten them about their "Indian self" (Srinivas, 2006). This thus accounts for the considerable influence that Indian parents wield over children regarding their food choices, as families encourage children to eat traditional Indian food at the dining table (Srinivas, 2006).

Therefore, since Indian parents are cooking the dinner and purchasing food, it is little wonder that cost and convenience issues would not be considered of significance to the Gen $\mathrm{Z}$ respondents. Instead of dismissing the importance of these factors that rate relatively poorly among the respondents, plant-based meat companies need to reach out to the parents of the Gen $\mathrm{Z}$ population segment in their marketing approach and consider how to reshape their mentality towards food. How can they incorporate plant-based meat into the traditional culinary tradition?

\section{Influence of Factors on India's Gen Z Vegetarians' Purchasing Decisions of Plant-Based Meat}

Additional analyses were conducted to provide a more detailed picture of the respondents' differences by splitting the respondents between vegetarians and non-vegetarians. We begin with the vegetarians.

As shown in Figure 3, the factors, presented in order of magnitude from the most important to the least, are: animal welfare $(M=6.42 ; S D=1.40)$; environmental consciousness $(M=6.26 ; S D=1.26)$; health/safety $(M=5.98$; $S D=1.46)$; taste $(M=5.56 ; S D=1.80)$; convenience $(M=5.32 ; S D=1.57)$; nutrition $(M=5.23 ; S D=1.41)$; cost $(M$ $=5.01 ; S D=1.84)$; food curiosity $(M=4.79 ; S D=1.72)$.

\begin{tabular}{|c|c|c|c|c|}
\hline & Mean & Standard Error & Median & Standard Deviation \\
\hline Nutrition & 5.227272727 & 0.173803542 & 5 & 1.411986648 \\
\hline Taste & 5.560606061 & 0.221384484 & 6 & 1.798536053 \\
\hline Food curiosity & 4.787878788 & 0.212121212 & 5 & 1.723280874 \\
\hline Animal welfare & 6.424242424 & 0.172815174 & 7 & 1.403957112 \\
\hline
\end{tabular}




\begin{tabular}{|l|c|c|c|c|} 
& & & & \\
\hline Health and safety & 5.984848485 & 0.179992779 & 7 & 1.462268251 \\
\hline Environmental consciousness & 6.257575758 & 0.154664244 & 7 & 1.256498261 \\
\hline Cost & 5.015151515 & 0.225932333 & 5.5 & 1.835482953 \\
\hline Convenience & 5.318181818 & 0.193313749 & 5 & 1.570488321 \\
\hline
\end{tabular}

Figure 3. Descriptive Statistics: Ratings of Factors on Vegetarian Respondents' Purchasing Decisions

A one-way ANOVA was undertaken to determine whether the mean differences are statistically significant. Table 4 shows that the mean differences in the ratings of the importance of factors are significant $($ see Figure 4$): F(7,520)=$ 9.46 (higher than the $F$ critical value of 2.03$), p<.05$.

ANOVA

\begin{tabular}{|l|c|r|r|r|r|r|}
\hline Source of Variation & \multicolumn{1}{|c|}{ SS } & $d f$ & MS & F & P-value & F crit \\
\hline Between Groups & 163.3560606 & 7 & 23.33658009 & 9.466366789 & $4.42064 \mathrm{E}-11$ & 2.02717807 \\
\hline Within Groups & 1281.909091 & 520 & 2.46520979 & & & \\
& & & & & & \\
\hline Total & 1445.265152 & 527 & & & & \\
\hline
\end{tabular}

Figure 4. One-way ANOVA: Ratings of Factors on Vegetarian Respondents' Purchasing Decisions

Although the order of importance for the factors is similar to the combined group, the differences are revealing. Firstly, the most critical factor for the vegetarians is animal welfare $(M=6.40)$, with environmental consciousness coming in second $(M=6.26)$. Further, the mean ratings for these factors were higher than their corresponding ratings for the combined group - environmental consciousness $(M=6.01)$ and animal welfare $(M=5.97)$.

The emphasis on the environment and animal welfare is also reflected in the qualitative data:

It's all about the animals.

Plant-based meats are good for conservation of water and land.

These findings certainly reaffirm that these factors are powerful forces that drive vegetarians to purchase plant-based meat (Hopwood et al., 2020). In fact, this research study confirms the prevalent discourse on this topic that highlights the high environmental consciousness among Generation Z. According to Su et al. (2019), 92.8\% of Gen Z respondents considered environmental protection and health to be significant to their purchase decisions of sustainable food.

\section{Influence of Factors on India's Non-Vegetarian Gen Z's Purchasing Decisions of Plant-Based Meat}

Figure 5 presents the following results for non-vegetarians, with the ratings of the factors ranging from the most important to the least: taste $(M=6.00 ; S D=1.44)$; health/safety $(M=5.88 ; S D=1.37)$; environmental consciousness $(M=5.82 ; S D=1.36)$; animal welfare $(M=5.67 ; S D=1.49)$; nutrition $(M=5.33 ; S D=1.45)$; convenience $(M=$ $5.23 ; S D=1.61)$; food curiosity $(M=4.97 ; S D=1.58)$; $\operatorname{cost}(M=4.65 ; S D=1.89)$. 


\begin{tabular}{|c|c|c|c|c|}
\hline & Mean & Standard Error & Median & Standard Deviation \\
\hline Nutrition & 5.330357143 & 0.136835673 & 5.5 & 1.448132646 \\
\hline Taste & 6.008928571 & 0.136309805 & 7 & 1.442567379 \\
\hline Food curiosity & 4.972972973 & 0.150052931 & 5 & 1.580905721 \\
\hline Animal welfare & 5.669642857 & 0.140890481 & 6 & 1.491044696 \\
\hline Health and safety & 5.883928571 & 0.129811228 & 6 & 1.373792906 \\
\hline $\begin{array}{c}\text { Environmental conscious- } \\
\text { ness }\end{array}$ & 5.821428571 & 0.128858895 & 6 & 1.363714361 \\
\hline Cost & 4.651785714 & 0.178794504 & 5 & 1.892183168 \\
\hline Convenience & 5.234234234 & 0.153023021 & 5 & 1.612197568 \\
\hline
\end{tabular}

Figure 5. Descriptive Statistics: Ratings of Factors on Non-Vegetarian Respondents' Purchasing Decisions

A one-way ANOVA test was conducted to determine whether these mean differences are significant. The results in Figure 6 show that the differences in the importance of factors are significant: $F(7,886)=10.94$ (higher than the $F$ critical value of 2.02), $p<.05$.

ANOVA
\begin{tabular}{|c|c|c|c|c|c|c|}
\hline $\begin{array}{c}\text { Source of Varia- } \\
\text { tion }\end{array}$ & SS & $d f$ & $M S$ & $F$ & P-value & F crit \\
\hline Between Groups & 180.3163254 & 7 & 25.75947505 & 10.94774079 & $2.62629 \mathrm{E}-13$ & 2.019897115 \\
\hline Within Groups & 2084.712757 & 886 & 2.352948936 & & & \\
\hline Total & 2265.029083 & 893 & & & & \\
\hline
\end{tabular}

Figure 6. One-way ANOVA: Ratings of Factors on Non-Vegetarian Respondents' Purchasing Decisions

Taste and safety are the most significant factors for non-vegetarians in contrast to animal welfare for vegetarians. Generally, while non-vegetarians look for how closely plant-based meat replicates traditional meat in terms of taste and safety, vegetarians are focused on the ethical aspects of plant-based meat. The results for the non-vegetarians align with a respondent's statement: "The product must be at least 95 percent close to what a conventional meat product would be. It should have the same nutrients, level of health, taste and affordability." Therefore, these findings highlight the need for plant-based meat companies to have a differentiated marketing approach for vegetarians and non-vegetarians, given that different factors influence their purchasing decisions.

Although environmental consciousness and health/safety remain consistently high across all three samples, including non-vegetarians, health and safety are more prominent for non-vegetarians $(M=5.88)$ due to the ongoing COVID-19 pandemic than environmental consciousness $(M=5.82)$. Zoonotic diseases are caused by germs that pass between animals and humans. Such a transfer has been escalated by corporatized meat production, with potential insanitary conditions and unsafe sale of meat posing a danger to human lives (Komba et al., 2012). Therefore, in their marketing strategies, plant-based meat companies could highlight potential health and safety risks associated with 
conventional meat, while offering plant-based meat as a cleaner and safer option. This will spread more awareness about plant-based meat's benefits and encourage consumers to purchase it as an alternative to conventional meat.

\section{Impact of Factors on the Likely Frequency of Weekly Consumption of Plant-Based Meat}

A multiple regression analysis was conducted to predict the effects of the respondents' ratings of the influencing factors on their likely frequency of weekly plant-based meat consumption (the number of meals). Of the eight factors, only taste was found to be statistically significant and associated with how often people are willing to incorporate plant-based meat into their diet (see Figure 7):

$b=0.35, t(141)=2.39$ (higher than the critical value of 1.97$), p=.02$.

\begin{tabular}{|c|c|c|c|c|c|}
\hline \multicolumn{2}{|c|}{ Regression Statistics } & & & & \\
\hline Multiple R & 0.3526 & & & & \\
\hline R Square & 0.1243 & & & & \\
\hline Adjusted $\mathrm{R}$ & & & & & \\
\hline Square & 0.0746 & & & & \\
\hline Standard Er- & & & & & \\
\hline ror & 2.0954 & & & & \\
\hline Observations & & & & & \\
\hline \multicolumn{6}{|l|}{ ANOVA } \\
\hline & $d f$ & $S S$ & $M S$ & $F$ & Significance \\
\hline \multirow{3}{*}{ Regression } & \multirow{3}{*}{8} & \multirow{3}{*}{87.94206087} & 10.9927576 & 2.50360 & 0.01423168 \\
\hline & & & 1 & 0011 & 7 \\
\hline & & & 4.39078030 & & \\
\hline Residual & 141 & 619.1000225 & 1 & & \\
\hline Total & 149 & 707.0420833 & & & \\
\hline
\end{tabular}

\begin{tabular}{|c|c|c|c|c|c|c|}
\hline & Coefficients & Standard Error & $t$ Stat & $P$-valuc & ower 95\% & Upper 95\% \\
\hline & - & 1.16245458 & & & - & 0.741538 \\
\hline \multirow[t]{2}{*}{ Intercept } & 1.556554815 & 7 & -1.339024193 & 0.182717488 & 3.854647892 & 262 \\
\hline & & 0.13569516 & & & - & 0.346585 \\
\hline \multirow[t]{2}{*}{ Nutrition } & 0.078325316 & 4 & 0.577215232 & 0.564714565 & 0.189934728 & 359 \\
\hline & & 0.14743924 & & & & 0.644115 \\
\hline Taste & 0.352638333 & 6 & 2.391753509 & 0.018086977 & 0.061161046 & 621 \\
\hline Food curios- & - & 0.11593031 & & & - & 0.206566 \\
\hline ity & 0.022619663 & 2 & -0.195114308 & 0.845584335 & 0.251805947 & 622 \\
\hline Animal wel- & & 0.18615270 & & & - & 0.687462 \\
\hline \multirow[t]{2}{*}{ fare } & 0.319451148 & 4 & 1.716070415 & 0.088345416 & 0.048559994 & 29 \\
\hline & - & 0.15164746 & & & - & 0.270113 \\
\hline Health & 0.029682887 & 9 & -0.195736116 & 0.845098515 & 0.329479544 & 77 \\
\hline \multicolumn{7}{|l|}{$\begin{array}{l}\text { Environmen- } \\
\text { tal }\end{array}$} \\
\hline conscious- & - & & & & & 0.393122 \\
\hline \multirow[t]{2}{*}{ ness } & 0.025188627 & 0.21159603 & -0.119041115 & 0.905412216 & 0.443499482 & 227 \\
\hline & & 0.11912300 & & & & 0.448351 \\
\hline Cost & 0.212853328 & 3 & 1.786836483 & 0.076112498 & 0.022644688 & 345 \\
\hline
\end{tabular}


Convenience $\quad-0.071483659$

Figure 7. Impact of the Factors on Likely Frequency of Weekly Consumption of Plant-Based Meat

The regression analysis was done again, with taste as the only independent variable. The predictive effect of taste was confirmed: $b=0.36, t(148)=2.98$ (higher than critical value of 1.97), $R^{2}=0.06, F(1,148)=8.91, p<.01$ (see Figure 8). Essentially, taste accounts for 6 percent of the respondents' anticipated frequency of plant-based meat consumption weekly.

\begin{tabular}{lr}
\hline \multicolumn{2}{c}{ Regression Statistics } \\
\hline Multiple R & 0.238301338 \\
R Square & 0.056787528 \\
Adjusted & R \\
Square & 0.050414471 \\
Standard Error & 2.122738719 \\
Observations & 150 \\
\hline
\end{tabular}

\begin{tabular}{lrrrrr} 
ANOVA & \multicolumn{6}{c}{ SS } & MS & $F$ & Significance $F$ \\
\hline & $d f$ & & & & \\
Regression & 1 & 3 & 40.1511720 & & \\
& & 666.890911 & & & \\
Residual & 148 & 3 & 4.506019671 & & \\
& & 707.042083 & & & \\
Total & 149 & 3 & & & \\
\hline
\end{tabular}

\begin{tabular}{|c|c|c|c|c|c|c|}
\hline & & Standard & & & & \\
\hline & Coefficients & Error & t Stat & $P$-value & Lower 95\% & Upper 95\% \\
\hline & & 0.76118193 & & & & \\
\hline Intercept & 0.859182239 & 6 & 1.128747542 & 0.260830663 & -0.645006506 & 2.363370984 \\
\hline & & 0.12380625 & & & & \\
\hline Taste & 0.369568668 & 1 & 2.985056611 & 0.003318374 & 0.124912351 & 0.614224986 \\
\hline
\end{tabular}

Figure 8. Impact of Taste on Likely Frequency of Weekly Consumption of Plant-Based Meat

The linear equation for calculating the weekly frequency of plant-based meat consumption is as follows: weekly frequency of meat consumption $=0.86+0.37 *$ (rating on importance of taste). For example, if an individual were to rate the importance of taste as "7", then his/her likely consumption of plant-based meat weekly would be around 3 meals per week. Conversely, if the individual rates the importance of taste as "1", his/her consumption would likely be about 1 meal a week. While this equation thus helps to point out the importance of "taste" as a factor, it is also critical to highlight that this factor only accounts for $6 \%$ of the weekly consumption. Therefore, other factors still need to be identified. 


\section{Impact of the Factors on the Respondents' Determination of a Price for a Plant-Based Burger}

A second regression analysis assessed how the influencing factors on Gen Z's purchasing decisions for plant-based meat would impact the price they were willing to pay for a plant-based meat burger, versus a conventional burger that costs INR 200.

Of the eight factors, only environmental consciousness was statistically significant and associated with how much respondents were willing to pay for plant-based meat (see Figure 9):

$b=29.7, t(120)=2.84$ (higher than critical value of 1.98), $p<.01$.

\begin{tabular}{lr}
\hline \multicolumn{2}{c}{ Regression Statistics } \\
\hline Multiple R & 0.380361029 \\
R Square & 0.144674512 \\
Adjusted R & \\
Square & 0.087652813 \\
Standard Er- & \\
ror & 88.77319764 \\
Observations & 129 \\
\hline
\end{tabular}

ANOVA

\begin{tabular}{lrrrrc}
\hline & \multicolumn{1}{c}{ S } & \multicolumn{2}{c}{ Significance } \\
& $d f$ & & MS & $F$ & $F$ \\
\hline Regression & 8 & 159957.8605 & 19994.73256 & 2.537183465 & 0.01376447 \\
\hline Residual & 120 & 945681.6744 & 7880.68062 & & \\
\hline Total & 128 & 1105639.535 & & & \\
\hline
\end{tabular}

\begin{tabular}{lcccccr}
\hline & Coefficients & $\begin{array}{c}\text { Standard Er- } \\
\text { ror }\end{array}$ & t Stat & P-value & Lower 95\% & Upper 95\% \\
\hline Intercept & 203.9000505 & 55.39101746 & 3.68110318 & 0.000349285 & 94.2296909 & 313.5704102 \\
\hline Nutrition & 8.916303457 & 7.008560202 & 1.272201879 & 0.205761146 & -4.960157982 & 22.7927649 \\
\hline Taste & -6.875056499 & 6.606419726 & -1.040662989 & 0.300124162 & -19.95530778 & 6.205194785 \\
\hline $\begin{array}{l}\text { Food curi- } \\
\text { osity }\end{array}$ & -1.732850197 & 5.326859611 & -0.325304274 & 0.745517295 & -12.2796615 & 8.81396111 \\
\hline $\begin{array}{l}\text { Animal } \\
\text { welfare }\end{array}$ & -10.49889945 & 9.485485481 & -1.106838387 & 0.270577653 & -29.27950056 & 8.281701662 \\
\hline $\begin{array}{l}\text { Health and } \\
\text { safety }\end{array}$ & 2.494317306 & 6.657556887 & 0.374659556 & 0.708574961 & -10.687182 & 15.67581661 \\
\hline $\begin{array}{l}\text { Environ- } \\
\text { mental con- } \\
\text { sciousness }\end{array}$ & 29.70250736 & 10.44055389 & 2.84491682 & 0.005224894 & 9.030937275 & 50.37407744 \\
\hline \begin{tabular}{l} 
Cost \\
\hline $\begin{array}{l}\text { Conven- } \\
\text { ience }\end{array}$
\end{tabular} & -6.664261495 & 5.969423247 & -1.116399561 & 0.266481593 & -18.48330408 & 5.154781093 \\
\hline
\end{tabular}

Figure 9. Impact of Factors on Respondents' Pricing of the Plant-based Burger 
Another regression analysis was conducted using only environmental consciousness to predict its association with how much respondents were willing to pay for a plant-based meat burger. The predictive significance of environmental consciousness is as follows (see Figure 10): $b=20.22, t(127)=3.29$ (higher than critical value of 1.98 ), $R^{2}=0.08$, $F(1,127)=10.88, p<.01$.

\begin{tabular}{lr}
\hline \multicolumn{2}{c}{ Regression Statistics } \\
\cline { 1 - 1 } Multiple R & 0.28094625 \\
R Square & 9 \\
Adjusted $\quad \mathrm{R}$ & 0.07167828 \\
Square & 7 \\
& 89.5470017 \\
Standard Error & 5 \\
Observations & 129 \\
\hline
\end{tabular}

\begin{tabular}{|c|c|c|c|c|c|c|}
\hline \multicolumn{7}{|l|}{ ANOVA } \\
\hline & \multirow[b]{2}{*}{$d f$} & \multirow[b]{2}{*}{$S S$} & \multirow[b]{2}{*}{$M S$} & & \multirow{2}{*}{$\begin{array}{c}\text { Significance } \\
F\end{array}$} & \\
\hline & & & & $F$ & & \\
\hline & & & & 10.8832340 & & \\
\hline Regression & 1 & 87269.0135 & 87269.0135 & 3 & 0.00125933 & \\
\hline Residual & 127 & 1018370.521 & 8018.665523 & & & \\
\hline \multirow[t]{3}{*}{ Total } & 128 & 1105639.535 & & & & \\
\hline & Coefficients & Standard Error & $t$ Stat & $P$-value & Lower 95\% & Upper 95\% \\
\hline & & & & 0.00045870 & 61.4758589 & 211.778806 \\
\hline Intercept & 136.6273328 & 37.97793207 & 3.597545347 & 5 & 3 & 7 \\
\hline Environmental & & & & & 8.09045868 & 32.3445133 \\
\hline consciousness & 20.21748602 & 6.128415007 & 3.298974694 & 0.00125933 & 9 & 5 \\
\hline
\end{tabular}

Figure 10. Impact of Environmental Consciousness on Respondents' Pricing of the Plant-based Burger

The linear equation is as follows:

Price of plant-based meat burger $=20.22 *$ (rating on importance of environmental consciousness) +137 .

These results provide companies with a sense of how much people who are generally environmentally conscious would be willing to spend on plant-based meat. For example, if someone rated the importance of environmental consciousness as "6" (on a scale of 0-7), then the price they would be willing to pay for a plant-based meat burger is INR258, a 28\% premium to an INR 200 conventional meat burger. Through this equation, it is fair to observe that an individual who is more environmentally conscious is willing to invest more in a plant-based meat burger. Conversely, if someone rates the importance of environmental consciousness as a " 3 ", then the price they would be willing to pay is INR 198, which is relatively close to the original price of INR 200. This result suggests that one who is not concerned about the environment is less likely to pay a premium price for plant-based meat. This observation is consistent with the ANOVA analysis results, wherein increasing concern for the environment among Gen $\mathrm{Z}$ is a key influencer for their purchase of plant-based meat. Nonetheless, it is essential to note that environmental consciousness only accounts for $8 \%$ of the cost predictions for a burger; thus, other factors still need to be identified. 
Impact of the Factors on the Non-Vegetarians Respondents' Determination of a Price for a PlantBased Burger

A separate multiple regression analysis was used to analyze which factors would influence non-vegetarians' perspective on a reasonable price for a plant-based meat burger. Within this group, the following factors were found to be statistically significant : nutrition, $b=20.40, t(72)=2.28$ (higher than critical value of 1.99 ), $p=.02$; and convenience: $b=-21.75, t(72)=-2.17$ (higher than $t$ critical value of 1.99), $p=.03$ (see Figure 11).

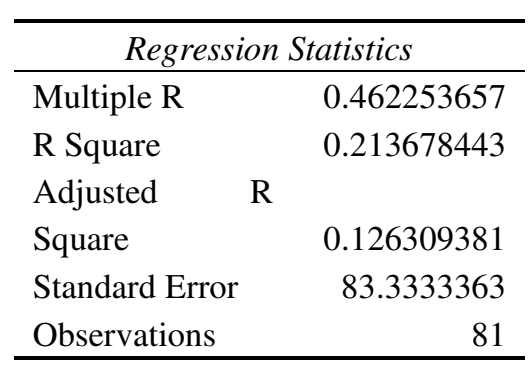

ANOVA

\begin{tabular}{|c|c|c|c|c|c|c|}
\hline & $d f$ & $S S$ & $M S$ & $F$ & $\begin{array}{c}\text { Significance } \\
F\end{array}$ & \\
\hline & & 135872.186 & & 2.44569918 & & \\
\hline \multirow[t]{2}{*}{ Regression } & 8 & 6 & 16984.02332 & 4 & 0.021175881 & \\
\hline & & 500000.035 & & & & \\
\hline \multirow[t]{2}{*}{ Residual } & 72 & 6 & 6944.44494 & & & \\
\hline & & 635872.222 & & & & \\
\hline \multirow[t]{4}{*}{ Total } & 80 & 2 & & & & \\
\hline & & Standard & & & & \\
\hline & Coefficients & Error & $t$ Stat & $P$-value & Lower 95\% & Upper $95 \%$ \\
\hline & & 78.9636135 & & & - & \\
\hline \multirow[t]{2}{*}{ Intercept } & 108.3775396 & 3 & 1.372499747 & 0.17416839 & 49.03354704 & 265.7886263 \\
\hline & & 8.91546657 & & 0.02509172 & & \\
\hline \multirow[t]{2}{*}{ Nutrition } & 20.39632796 & 2 & 2.287746558 & 7 & 2.623670171 & 38.16898575 \\
\hline & & 10.8685739 & & 0.37547026 & & \\
\hline \multirow[t]{2}{*}{ Taste } & 9.69260664 & 8 & 0.891801138 & 1 & -11.9734996 & 31.35871288 \\
\hline & & 6.40081250 & & 0.24261025 & & \\
\hline \multirow[t]{2}{*}{ Food curiosity } & 7.541212015 & 5 & 1.178164805 & 8 & -5.21857451 & 20.30099854 \\
\hline & & 11.5603242 & - & 0.89548186 & - & \\
\hline \multirow[t]{2}{*}{ Animal welfare } & -1.524064891 & 2 & 0.131835826 & 6 & 24.56915005 & 21.52102026 \\
\hline & & 8.16358666 & - & 0.11283874 & & \\
\hline Health and safety & -13.10376851 & 2 & 1.605148455 & 8 & -29.3775811 & 3.17004407 \\
\hline Environmental & & 11.9747949 & & 0.10410335 & & \\
\hline \multirow[t]{2}{*}{ consciousness } & 19.71161982 & 1 & 1.646092477 & 9 & -4.15969755 & 43.58293718 \\
\hline & & 7.56652918 & & 0.42693696 & - & \\
\hline \multirow[t]{2}{*}{ Cost } & 6.045412002 & 9 & 0.798967644 & 7 & 9.038188261 & 21.12901227 \\
\hline & & 10.0318181 & - & 0.03343756 & - & \\
\hline Convenience & -21.75246445 & 5 & 2.168347165 & 7 & 41.75052844 & -1.754400459 \\
\hline
\end{tabular}


Figure 11. Regression: Impact of Factors on Non-Vegetarian Respondents' Pricing of the Plant-based Burger

A regression was conducted again by using only the factors of nutrition and convenience to predict their impact on the price that non-vegetarians would be willing to pay for a plant-based meat burger. Both nutrition and convenience were statistically significant in the second regression as well (see Figure 12 ): nutrition, $b=24.76, t(78)=2.96$ (higher than critical value of 1.99$), \mathrm{R}^{2}=0.10, F(2,78)=4.57, p<.01$; convenience, $b=-15.28, t(78)=-2.07$ (absolute value is higher than critical value of 1.99$), \mathrm{R}^{2}=0.10, F(2,78)=4.57, p=.04$.

\begin{tabular}{lr}
\hline \multicolumn{2}{c}{ Regression Statistics } \\
\hline Multiple R & 0.323931244 \\
R Square & 0.104931451 \\
Adjusted $\quad \mathrm{R}$ & \\
Square & \\
Standard Error & 85.42122081 \\
Observations & 81 \\
\hline
\end{tabular}

ANOVA

\begin{tabular}{|c|c|c|c|c|c|}
\hline & $d f$ & $S S$ & $M S$ & $F$ & $\begin{array}{c}\text { Significance } \\
F\end{array}$ \\
\hline & & 66722.9949 & & 4.57208176 & \\
\hline \multirow[t]{2}{*}{ Regression } & 2 & 7 & 33361.49748 & 6 & 0.013255484 \\
\hline & & 569149.227 & & & \\
\hline \multirow[t]{2}{*}{ Residual } & 78 & 3 & 7296.784965 & & \\
\hline & & 635872.222 & & & \\
\hline Total & 80 & 2 & & & \\
\hline
\end{tabular}

\begin{tabular}{lrrrrrr}
\hline & \multicolumn{7}{c}{ Standard } & & & & \\
& Coefficients & Error & $t$ Stat & P-value & Lower 95\% & Upper 95\% \\
\hline \multirow{2}{*}{ Intercept } & & 42.5166082 & & & & \\
& 205.8256648 & 6 & 4.841065015 & $6.4024 \mathrm{E}-06$ & 121.1815999 & 290.4697297 \\
Nutrition & & 8.36705859 & & 0.00408847 & & \\
& 24.75568317 & 8 & 2.958707995 & 3 & 8.098149088 & 41.41321726 \\
Convenience & & 7.36192761 & - & 0.04122487 & - & -0.624079767 \\
\hline
\end{tabular}

Figure 12. Regression: Impact of Nutrition and Convenience on Non-Vegetarian Respondents' Pricing of the Plantbased Burger

The following linear equation provides an association between nutrition, convenience, and its relationship: Price of plant-based meat burger $=24.76 *$ (rating on importance of nutrition $)-15.28 *$ (Rating on convenience $)+206$. For instance, someone who rates the importance of nutrition as " 7 " and convenience as " 1 " would be willing to purchase a plant-based meat burger at INR364, an $81 \%$ premium on a conventional burger (INR 200). While nutrition is not among the top factors influencing Gen Z's purchasing decisions of plant-based meat in the ANOVA, this regression illustrates that the respondents who value nutrition are willing to pay a premium on plant-based meat as a substitute for meat-based burgers. This could be an opportunity for companies to target nutrition-oriented young adults as a niche market. 
Additionally, it is noticeable that an individual who rates convenience at the highest value of "7" would have to rate nutrition at "4" to be willing to purchase a plant-based meat burger at INR 197, a price that is close to the value of an INR200 burger with conventional meat. Therefore, this equation relating a consumer's opinions about nutrition and convenience regarding plant-based meat can help companies with their pricing of plant-based burgers for different buyers. Nonetheless, as nutrition and convenience only account for $10 \%$ of the price predictions for a plant-based meat burger, additional factors should be identified.

\section{Conclusion}

This research study aimed to evaluate the importance of factors in influencing India's Gen Z's decision to purchase plant-based meat in India. Based on the results, every null hypothesis is rejected. Environmental consciousness and health/safety were rated as the most important factors influencing the Gen Z respondents' attitudes towards plantbased meat. Conversely, cost, convenience, and food curiosity had generally lower ratings. These ratings highlight the need for plant-based companies to consider India's unique sociocultural context, whereby $82 \%$ of adults aged between 22 and 29 live with their parents (CBRE, 2016), who play decisive roles in meal choices and food purchases.

There are some noteworthy distinctions when examining the respondents' ratings as a combined group, vegetarians, and non-vegetarians. These findings can help plant-based companies structure their manufacturing, marketing, and distribution strategies for India's market, as discussed below.

- Gen $\mathbf{Z}$ as a whole: Overall, the results illustrate that environmental consciousness and health are the most critical factors that Gen $\mathrm{Z}$ consider in their decision to purchase plant-based meat. Furthermore, the findings suggest that more environmentally-conscious people are willing to pay more for plant-based meat. In India, we need to consider two separate market segments - the older Gen Z population living in non-traditional family contexts, i.e., independently, and the younger Gen Z population still living along with their families of origin.

The older Gen Z population in India, who live independently of their parents, would likely consume plant-based food in similar ways to their counterparts abroad. Therefore, companies should sell plant-based meat in food formats that appeal to the older Indian Gen Z population (burgers, sandwiches, etc.) by highlighting its environmental benefits. Specifically, the respondents had pinpointed social media as a key player in influencing the perceptions of Gen Z:

[There should be] awareness about plant-based meat. I mostly get to know about new products through social media, YouTube, and friends.

Often people tend to consume foods that are consumed widely by their peers. Foods such as avocados are something which had previously got a lot of demand.

Companies need to consider a differentiated approach while targeting the younger Gen $\mathrm{Z}$ population who live with their parents. Specifically, the low ratings of cost and convenience can be explained by the fact that most young Gen Z still live with their parents, who are generally in charge of both organizing and purchasing food for the family. The parents' affiliative desire to maintain traditional food habits and their broad influence on food choices could also be a possible reason for inhibiting the Gen Z's food curiosity. Therefore, these results highlight Indian parents as a critical market segment that plant-based meat companies need to target culturally. Plant-based meat companies could consider the following recommendations in addressing this particular audience: 
1) Companies should incorporate plant-based food into traditional Indian dishes as they are more likely to appeal to Gen Z's parents. Instead of just offering plant-based burgers, companies could offer plant-based meat tikka or samosas — familiar Indian dishes — that Indian parents would be more likely to be interested in purchasing and incorporating into their meals.

2) Companies can also market plant-based meat to Indian restaurants to increase their exposure and availability. As exposure and popularity of plant-based meat increases within families (a factor mentioned in qualitative data), it is likely that Gen Z, who are responsive to trends, along with their parents, will explore these new alternatives when they dine outside. Such a strategy would be a win-win situation for both restaurants (allowing them to offer unique dishes to their customers) and plant-based companies.

- Vegetarians: The most important influencing factor for the vegetarians is animal welfare, followed by environmental consciousness, and their mean ratings were higher than corresponding ratings for the combined group. These findings depict the importance that vegetarians place on ethical standards when considering plant-based meat. Therefore, when companies focus on selling plant-based meat to a vegetarian audience, promoting the benefits of animal welfare and the environment needs to be the mainstay of their marketing strategies.

- Non-Vegetarians: The results for non-vegetarians illustrate that health/safety and taste were the two most significant factors for their decision to purchase plant-based meat. Given the ongoing COVID-19 pandemic, which has heightened the awareness about zoonotic diseases, non-vegetarians could be more open to plant-based meat if its taste, texture, and nutritional value are close to that of conventional meat. Moreover, the study found that respondents who valued nutrition highly and placed less importance on convenience are willing to pay a higher price for plant-based meat than even vegetarians who rate environment consciousness at the optimal level. Based on this information, plant-based companies should consider the following while targeting this particular customer segment:

1) Companies should highlight the plant-based meat's similarity to conventional meat, in terms of taste and nutrition. In fact, marketing by emphasizing the nutrients and proteins in plant-based meat could allow for a premium pricing strategy for certain segments. Based on the consumer's ratings on the importance of taste (high among non-vegetarians), nutrition, and convenience, companies could create different profiles for consumers and price their plant-based meat accordingly. For example, a potential niche market to be explored is nutrition-oriented young adults and sports enthusiasts.

2) Companies should educate the public on the health and safety risks associated with the production and consumption of conventional meat, and promote plant-based meat as a safer alternative.

With rising environmental consciousness, concern for animal welfare and health/ safety risks associated with conventional meat, India presents a significant opportunity for plant-based meat companies. Gen Z, as the future decision-makers and head of households, are likely to play a significant role in the adoption of plant-based meat. Companies that carefully consider the various segments' cultural and specific preferences and employ targeted customer strategies to promote their products would be well-positioned to capitalize on this rapidly growing plant-based meat market.

\section{Acknowledgments}

I would like to thank Ms. Kay Ying Choo for her guidance and constant support in completing this research project. 


\section{References}

Animal Legal Defense Fund. (n.d.) Innovation in food production: Plant-based meats. https://aldf.org/article/innovation-in-food-production-plant-based-meats/

Bridgeman, L. (2020, August 13). What is plant-based meat: A look at the future of food. Sentient Media. https://sentientmedia.org/plant-based-meats/

Bradbury, J. (2004). Taste perception: Cracking the code. PloS Biol, 2(3), e64. https://doi.org/10.1371/journal.pbio.0020064

Bryant, C., Szejda, K., Parekh, N., Deshpande, V., \& Tse, B. (2019). A survey of consumer perceptions of plantbased and clean meat in the USA, India, and China. Frontiers in Sustainable Food Systems, 4. https://doi.org/10.3389/fsufs.2019.00011

Bollani, L., Bonadonna, A., \& Peira, G. (2019). The millennials' concept of sustainability in the food sector. Sustainability, MDPI, 11(10), 2984-3003. https://doi.org/10.3390/su11102984

BritainThinks. (2019). Future consumer: Food and generation Z. https://www.food.gov.uk/sites/default/files/media/document/fsa191102bt-gen-z_rea_full-report_081019-final.pdf

CBRE Global Research. (2016). Asia Pacific millennials: Shaping the future of real estate - Millennials in India. https://www.cbre.co.in/ko-kr/global/research-and-reports/2016-apac-millennial-survey/india

Chadda, R., \& Deb, K. (2013). Indian family systems, collectivistic society and psychotherapy. Indian Journal of Psychiatry, 55(6), 299-309. 10.4103/0019-5545.105555

Department of Health. (n.d.). Nutrients. https://aldf.org/article/innovation-in-food-production-plant-based-meats/

Devlin, H. (2018, July 19). Rising global meat consumption will devastate environment. The Guardian. https://www.theguardian.com/environment/2018/jul/19/rising-global-meat-consumption-will-devastateenvironment

Dione, M., Ho, S., Figueiras, S., \& Perez, A. (2020). The Asia alternative protein industry report 2020. Queen Green Media. https://www.greenqueen.com.hk/wp-content/uploads/2020/02/The-Asia-Alternative-ProteinIndustry-Report-2020-New-Decade-New-Protein.pdf

FoodPrint. (2020). Animal welfare in food production. https://foodprint.org/the-total-footprint-of-our-food-system/issues/animal-welfare-in-food-production/

Gadenne, D. L., Kennedy, J., \& McKeiver, C. (2009). An empirical study of environmental awareness and practices in SMEs. Journal of Business Ethics, 84(1), 45-63. 10.1007/s10551008-9672-9

Ghvanidze, S., Velikova, N., Dodd, T., \& Oldewage-Theron., W. (2016, December 1). Consumers' environmental and ethical consciousness and the use of the related food product information: The role of perceived consumer effectiveness. Appetite, 107, 311-322. https://doi.org/10.1016/j.appet.2016.08.097 
Hancox, D. (2018, April 1). The unstoppable rise of veganism: How a fringe movement went mainstream. The Guardian. https://www.theguardian.com/lifeandstyle/2018/apr/01/vegans-are-coming-millennials-healthclimate-change-animal-welfare

Heilig, G. K. (1994). The greenhouse gas methane(CH): Sources and sinks, the impact of population growth, possible interventions. International Institute for Applied Systems Analysis Laxenburg, Austria, 16(2), 109-137. http://www.jstor.org/stable/27503384

Hopwood, C., Bleidorn, W., Schwaba, T., \& Chen, S. (2020). Health, environmental, and animal rights motives for vegetarian eating. PubMed Central, 15(4), 299-309. https://doi.org/10.1371/journal.pone.0230609

Hwang, J., You, J., Moon, J., \& Jeong, J. (2020). Factors affecting consumers' alternative meat buying intentions: Plant-based meat alternative and cultured meat. Sustainability, MDPI, 12(14), 5662-5688. https://doi.org/10.3390/su12145662

Ignaszewski, E. (2020, July 30). Meat-aisle merchandising catapults plant-based meat sales. The Good Food Institute. https://www.gfi.org/blog-merchandising-plant-based-meat

Insider Inc. (2017). Generation Z news: Latest characteristics. Business Insider. https://www.businessinsider.com/generation-z?IR=T

Jezerc, G. (2019, January 14). First Insight finds expectations for sustainable retail practices growing with the rise of Gen Z shoppers. BusinessWire. https://www.businesswire.com/news/home/20200114005180/en/FirstInsight-Finds-Expectations-for-Sustainable-Retail-Practices-Growing-with-the-Rise-of-Gen-Z-Shoppers

Komba, V. E., Komba, E., Mkupasi, E. \& Mbyuzi, A., Mshamu, S., Mzula, A., \& Luwumba, D. (2012). Sanitary practices and occurrence of zoonotic conditions in cattle at slaughter in Morogoro Municipality, Tanzania: Implications for public health. Tanzania Journal of Health Research, 14(2). https://doi.org/10.4314/thrb.v14i2.6

Markets And Markets Research. (2020). COVID-19 impact on plant-based meat market by raw material (soy, wheat, pea), product (burger patties, sausages, strips \& nuggets, meatballs), distribution channel (retail outlets, foodservice, e-commerce), and region - Global forecast to 2021. https://www.marketsandmarkets.com/Market-Reports/covid-19-impact-on-plant-based-meat-market-255440423.html

Markets And Markets Research Private Ltd. (2020b). Plant-based meat market by source (soy, wheat, pea, quinoa, oats, beans, nuts), product (burger patties, sausages, strips \& nuggets, meatballs), type (pork, beef, chicken, fish), process, and region - Global forecast to 2025. https://www.marketsandmarkets.com/Market-Reports/plant-based-meat-market-44922705.html

Miller, L., \& Lu, W. (2018, August 20). Gen Z is set to outnumber millennials within a year. Bloomberg. https://www.bloomberg.com/news/articles/2018-08-20/gen-z-to-outnumber-millennials-within-a-year-demographic-trends

Mousel, T., \& Tang, X. (2016). Analysis of consumer behavior towards plant-based meat and dairy alternatives market in Sweden [Unpublished Master's thesis]. Uppsala University. 
Nozaki, Y. (2016). The future of global meat demand - Implications for the grain market. Mitsui Global Strategic Studies Institute Monthly Report. Retrieved from https:/www.mitsui.com/mgssi/en/report/detail/ icsFiles/afieldfile/2016/11/08/161012m nozaki.pdf

Robinson, J. (2017, October 12). The health benefits of (the right kinds of) of meat. American Council of Exercise. https://www.acefitness.org/education-and-resources/lifestyle/blog/6602/the-health-benefits-of-the-rightkinds-of-meat/

Srinivas, T. (2006). As mother made it: The cosmopolitan Indian family, authentic food and the construction of cultural utopia. International Journal of Sociology of the Family, 32(2), 191-221. https:/www.jstor.org/stable/23030195

Su, C., Tsai, C., Chen, M., \& Lv, W. (2019). U.S sustainable food market Generation Z consumer segments. Sustainability, MDPI, 11(13), 3607-3621.

Szejda, K. \& Parry, J. (2020, March). Strategies to accelerate consumer adoption of plant-based meat. The Good Food Institute. https://doi.org/10.3390/su11133607

Szejda, K., Urbanovich, T., \& Wilks, M. (2020). Accelerating consumer adoption of plant-based meat. The Good Food Institute. https:/www.gfi.org/images/uploads/2020/02/NO-HYPERLINKED-REFERENCESFINAL-COMBINED-accelerating-consumer-adoption-of-plant-based-meat.pdf

The Good Food Institute. (2019). Plant-based meat for a growing world. https:/www.gfi.org/images/uploads/2019/08/GFI-Plant-Based-Meat-Fact-Sheet_EnvironmentalComparison.pdf?utm_source=blog\&utm_medium=website\&utm_campaign=pb-meat-sustainability.pdf

Whitnall, T., \& Pitts, N. (2020). Meat consumption. ABARES. https://www.agriculture.gov.au/abares/research-topics/agricultural-outlook/meat-consumption\#: :text=Global\%20meat $\% 20$ consumption $\% 20$ increased $\% 20$ by,growth $\% 20$ accounted $\% 20$ for $\% 20$ the $\% 20$ remainder.\&text $=$ This $\% 20$ increase $\% 20$ accounted $\% 20$ for $\% 2034 \% 25 \% 20$ of $\% 20$ global $\% 20$ consumption $\% 20$ growth

World Health Organization. (n.d.). Food safety. https://www.who.int/health-topics/food-safety/ 


\section{Appendix A}

Questionnaire

1. Are you familiar with the concept of "plant-based meat"?

2. When thinking about all the food and beverages you consume, please select the statement that best describes you:
a. Non-vegetarian
b. Vegetarian
c. Vegan
d. Other

3. Assuming plant-based meat becomes widely available, how likely are you to purchase plant-based meat, on a scale of "1" ("not likely") to "7" ("extremely likely")?

4. On a scale of 1-7, to what extent would you rate the importance of each factors in influencing your decision to purchase plant-based meat?
a. Nutrition
b. Taste
c. Food Curiosity
d. Animal Welfare
e. Health and Safety
f. Environmental consciousness
g. Cost
h. Convenience

5. Please elaborate on your ratings of the factors above. What other factors (not listed above) may influence your decision to purchase plant-based meat?

6. Assuming a conventional burger costs INR200, how much would you be willing to pay for a plant-based burger? What factors would influence your reasoning?

7. Assuming that you start to eat plant-based meat, how frequently will you eat it weekly (please enter number of meals per week)?

\section{Appendix B}

Participation Invitation Letter

Dear Invitee,

My name is Nikita Dhawan and I am a high school student in New Delhi. I am kindly requesting your participation in a research study that I am conducting on Gen Z's (age 15-25) attitudes towards plant-based meat. The intention of this study is to assess the factors influencing Gen Z's decisions to purchase plant-based meat as an alternative to conventional meat.

The study is completely anonymous and does not require you to provide your name or any other identifying information. Your participation in the research will be very valuable in exploring alternatives to conventional meat, which will promote human health, the environment, and animal welfare. 
Thank you for your time and participation.

Regards,

Nikita 